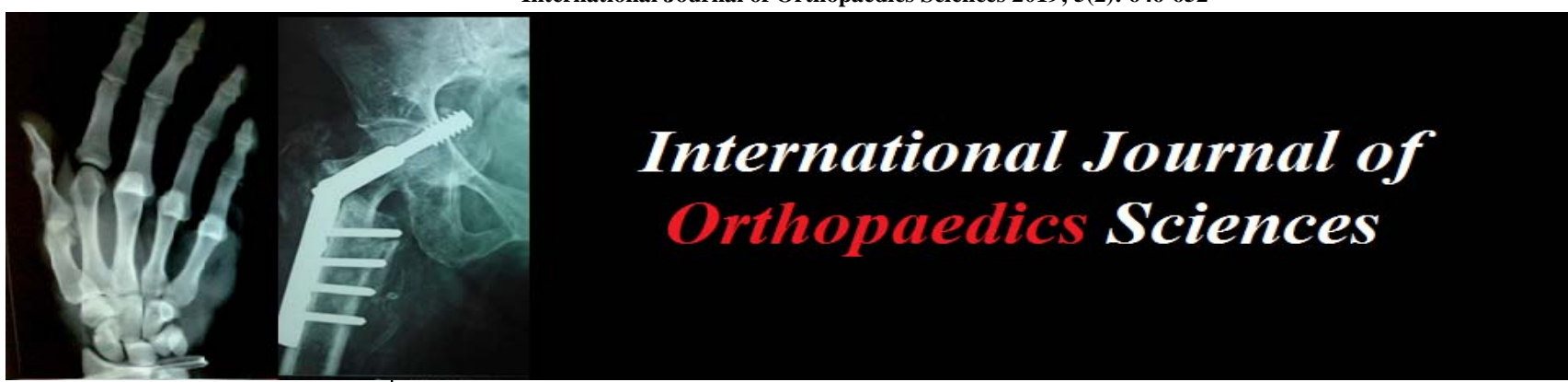

ISSN: $2395-1958$

IJOS 2019; 5(2): 646-652

(C) 2019 IJOS

www.orthopaper.com

Received: 18-02-2019

Accepted: 22-03-2019

Dr. Anantharaman C

Associate Professor,

Department of Orthopedics,

Tuticorin Medical College

Dr. Rohit S

Resident Department of Orthopedics, Balaji Medical

College, Thoothukudi,

Tamil Nadu, India

Dr. Mohan G

Assistant Professor, Department of Orthopedics, Kilpauk Medical College, Chennai, Tamil Nadu, India

Dr. Kathirazhagan S

Senior Resident Department of Orthopedics, Rathinamangalam,

Tamil Nadu, India
Correspondence

Dr. Rohit S

Resident Department of

Orthopedics, Balaji Medical

College, Thoothukudi,

Tamil Nadu, India

\section{A prospective study of functional outcome of distal fibula fractures with syndesmotic injury managed by anatomical locking compression plate and syndesmotic suture button fixation}

\author{
Dr. Anantharaman C, Dr. Rohit S, Dr. Mohan G and Dr. Kathirazhagan S
}

DOI: https://doi.org/10.22271/ortho.2019.v5.i2i.66

\section{Abstract}

Syndesmotic injury can occur after trauma to the ankle, both with and without a fracture. In fractures of the ankle, syndesmotic injury occurs in about $50 \%$ of type Weber B and in all type Weber C fractures. Syndesmotic diastasis left unnoticed can lead to persisting pain, instability and progressive arthritis. This study focusses on the application of syndesmotic suture button anchor as a fixation method for the syndesmotic joint diastasis. The syndesmotic button fixation does not convert the joint into a rigid articulation and still allows micro motion to happen. In this study, Distal fibular fractures with syndesmotic injuries are selected and anatomically precontoured locking compression plate is applied for fracture fixation and syndesmotic suture button fixation is done for the syndesmotic injury and their functional outcomes studied by various modalities.

Keywords: Syndesmotic injury, Ankle, suture button

\section{Introduction}

Ankle joint is a complex weight bearing joint. It enables lots of thrust forces to pass through the joint on weight bearing.

Syndesmotic injury can occur after trauma to the ankle, both with and without a fracture. Conventional treatment modality for fixation of the syndesmotic injury when diagnosed is with the help of screw fixation, one or two screws depending upon the fracture pattern and the instability. Screw fixation has been associated with many shortcomings as it converts the distal tibiofibular joint into a rigid joint and has got screw related complications like breakage, infection and difficulty at the time of removal.

This study focusses on the application of syndesmotic suture button anchor as a fixation method for the syndesmotic joint diastasis. The syndesmotic button fixation does not convert the joint into a rigid articulation and still allows micro motion to happen.

\section{Aim of the study}

To study the functional outcome of distal fibula fractures with syndesmotic injury managed by distal fibula anatomical locking compression plate and syndesmotic suture button fixation.

\section{Materials and methods}

This study was formally approved by the Ethical committee of Kilpauk Medical College and Hospital and was carried out under their guidance.

This prospective study was carried out at Department of Orthopaedics, Govt. Kilpauk Medical College and hospital, Chennai between September 2014- July 2018.

\section{Inclusion criteria}

A total sample size of 20 patients were included in this study who satisfied the following criterias.

1. Age above 18 years. 
2. Skeletally matured.

3. Distal fibula fractures with Weber B and Weber C type of Danis - Weber classification.

4. X-ray suggestive of associated syndesmotic injury.

MRI of the ankle was done wherever possible to diagnose syndesmotic ligament injury and intraoperative stress testing was done to confirm.

All the included patients were duly explained about the procedure and all the treatment options were explained.

\section{Exclusion criteria}

1. Weber A type Fractures

2. Distal fibula fracture without syndesmotic injury.

3. Pediatric and skeletally immature patients

4. Compound injuries

5. Associated neurovascular injuries

6. Pathological fractures

7. Old fractures

All the admitted patients were thoroughly evaluated by doing clinical examination and other injuries were rule out, the distal fibula fracture was initially immobilized by applying a short leg slab and was processed for surgery after preoperative evaluation and planning

With proper consent, patients involved in this study were posted for surgery with distal fibula locking compression plate and syndesmotic suture button fixation.

Post operatively, all the patients were advised to keep the limb elevated, intravenous antibiotic cover was provided till $5^{\text {th }}$ day and then it was converted to oral antibiotics. Postoperative $\mathrm{x}$-ray was taken on the next day after surgery.

Check dressing was done on the $2^{\text {nd }}$ and $5^{\text {th }}$ day. Patients were discharged after $5^{\text {th }}$ post-operative day and sutures were removed on the $12^{\text {th }}$ post-operative day.

Strict non- weight bearing was advised for the patients. Assisted ankle mobilization was initiated. Check x-ray was taken at 6 weeks.

Partial weight bearing was advised with support by 8 weeks. After confirming consolidation and radiological signs of union, full weight bearing was initiated from $12^{\text {th }}$ week onwards.

Functional outcome was done using the American Orthopaedic Foot and Ankle Society (AOFAS) - Ankle and hind foot scale scoring system.

Radiological outcome was observed based on the appearance of bridging callus and fracture line consolidation in successive follow up x-rays.

Clinical outcome was observed based on the absence of tenderness. Secondary outcomes were measured based on the perioperative data like duration of the surgery, amount of blood loss, length of the incision and complications like neurovascular injury, non-union, malunion, implant failure, infection.

\section{Case reports}

\section{Case 1}
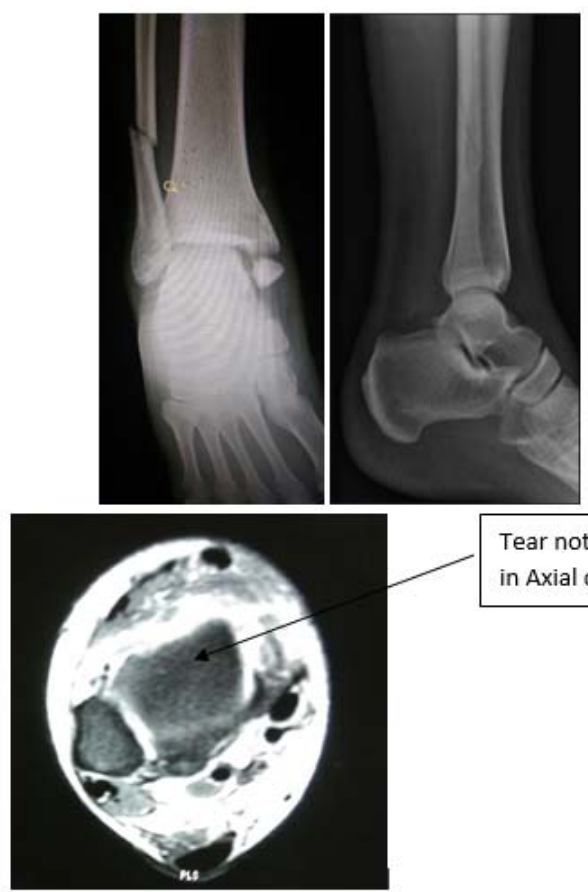

Tear noted in the ATFL

in Axial cuts

Immediate post op x-ray

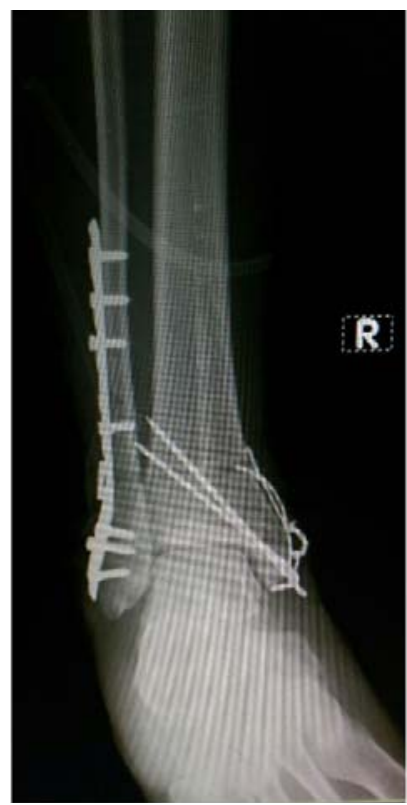

Mortise View

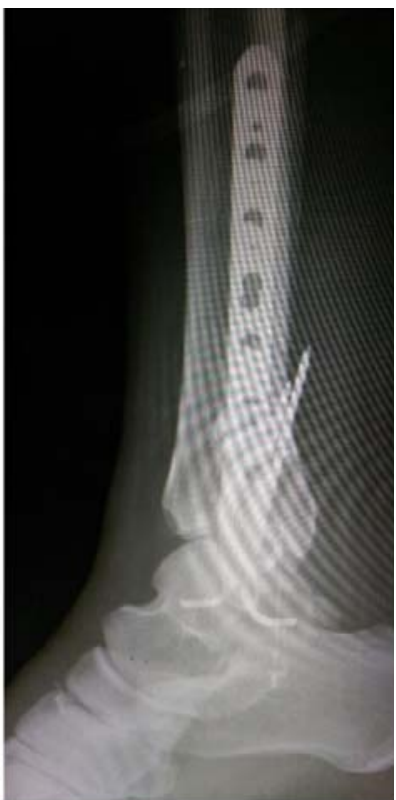

Lateral View 


\section{6 weeks follow up}

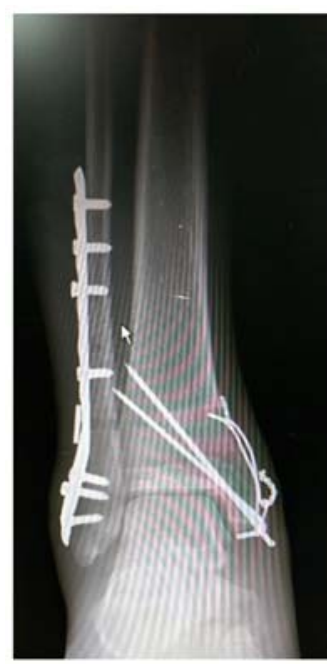

Ap View

3 months follow up

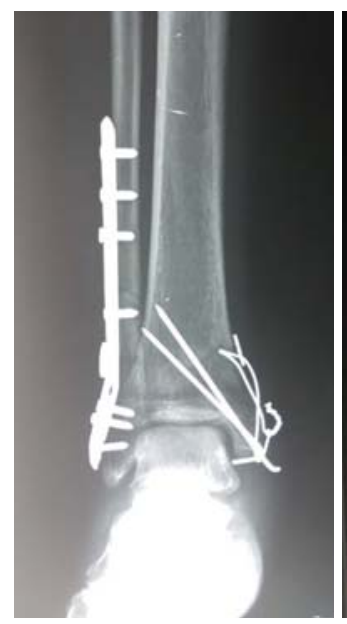

Mortise View

\section{6 months follow up}

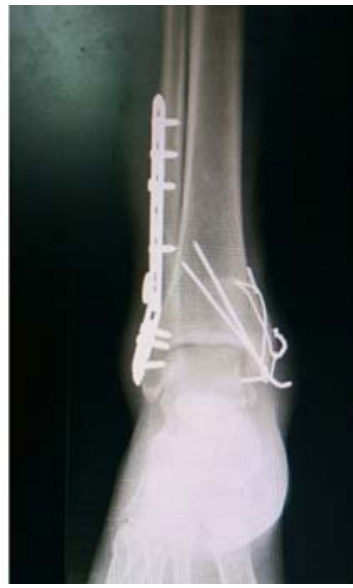

Ap View

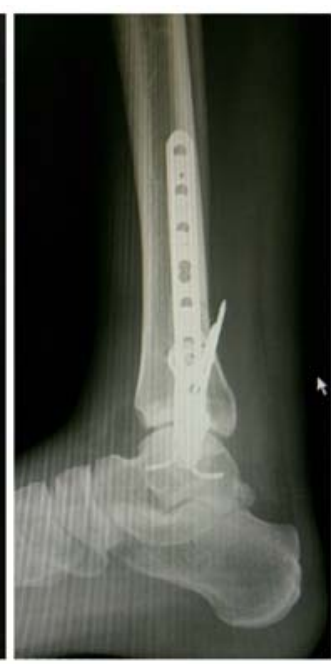

Lateral View

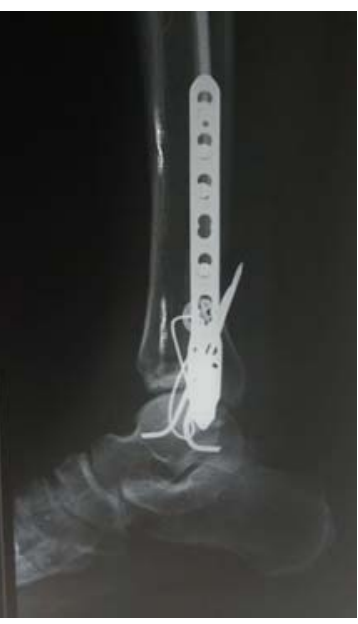

Lateral View

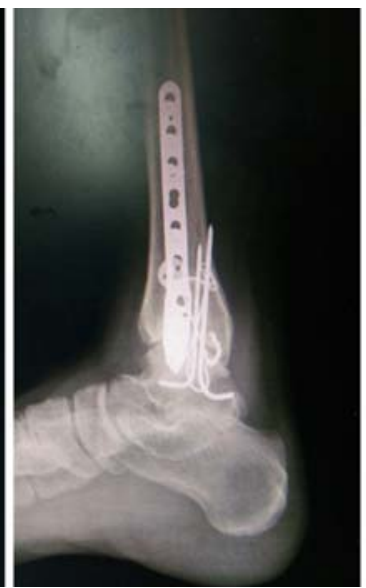

Lateral View

\section{Clinical photo results}
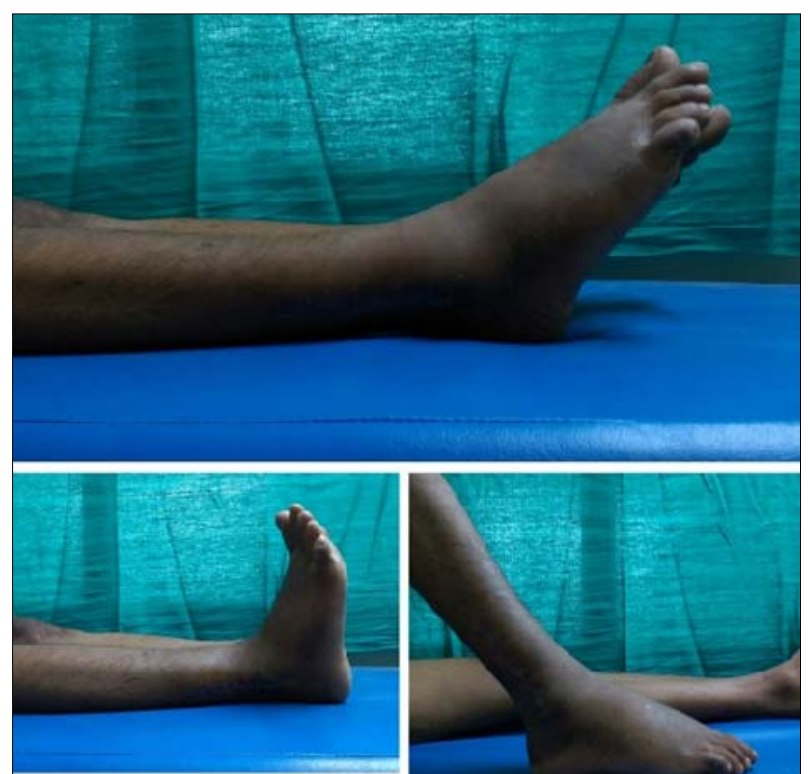

\section{Evaluation of pain}

\begin{tabular}{|c|c|c|c|}
\hline \multirow{2}{*}{ Pain Scale } & \multirow{2}{*}{ Score } & \multicolumn{2}{|c|}{ No Of Cases } \\
\cline { 3 - 4 } & & 3 Months & 6 Months \\
\hline No Pain & 40 & $13(65 \%)$ & $17(85 \%)$ \\
\hline Mild, Occasional & 30 & $7(35 \%)$ & $3(15 \%)$ \\
\hline Moderate, Daily & 20 & 0 & 0 \\
\hline Severe, Always Present & 0 & 0 & 0 \\
\hline
\end{tabular}

All the patients at the end of 6 months were comfortable to do their day to day activities without any pain. Only three patients had occasional pain on doing strenuous activities. On an average $65 \%$ of the patients were able to do pain free activities as early as 12 weeks, while other patients were also able to do similarly at the end of 6 months.

\section{Range of motion}

\begin{tabular}{|c|c|c|}
\hline Serial No & Movements & Average(Mean Plus Sd) \\
\hline 1 & Dorsiflexion & $17 \pm 1.788$ \\
\hline 2 & Plantarflexion & $30.5 \pm 1.466$ \\
\hline 3 & Inversion & $16.25 \pm 1.089$ \\
\hline 4 & Eversion & $16.45 \pm 0.920$ \\
\hline
\end{tabular}

At the end of 6 months all the patients had a normal range of movements, able to do their day to day activities. There was no stiffness or restriction of movements as mobilization was started early and physiotherapy was given adequately.

\section{Functional outcome}

\begin{tabular}{|c|c|c|c|c|}
\hline S. No & Result & Score & Cases & Percentage \\
\hline 1 & Excellent & $>90$ & 17 & $85 \%$ \\
\hline 2 & Good & $81-90$ & 3 & $15 \%$ \\
\hline 3 & Fair & $60-79$ & 0 & $0 \%$ \\
\hline 4 & Poor & $<60$ & 0 & $0 \%$ \\
\hline
\end{tabular}

17 Cases (85\%) had an excellent outcome.

3 cases (15\%) had a good outcome 
Statistics

1. Age vs time for union in weeks

\begin{tabular}{|c|c|c|c|c|c|c|}
\hline & \multicolumn{7}{|c|}{ 95\% Confidence Interval for Mean } \\
\hline & $\mathbf{N}$ & Mean & Std. Deviation & Std. Error & Lower Bound & Upper Bound \\
\hline up to 40 years & 5 & 10.40 & .894 & .400 & 9.29 & 11.51 \\
\hline 41-60 years & 10 & 11.80 & 1.135 & .359 & 10.99 & 12.61 \\
\hline 61 years \& above & 5 & 14.40 & .894 & .400 & 13.29 & 15.51 \\
\hline Total & 20 & 12.10 & 1.774 & .397 & 11.27 & 12.93 \\
\hline
\end{tabular}

\begin{tabular}{|c|c|c|c|c|c|}
\hline \multicolumn{7}{|c|}{ Time For Union In Weeks } \\
\hline & Sum Of Squares & Df & Mean Square & F & Sig. \\
\hline Between Groups & 41.800 & 2 & 20.900 & 19.739 & $\mathbf{. 0 0 0}$ \\
\hline Within Groups & 18.000 & 17 & 1.059 & & \\
\hline Total & 59.800 & 19 & & & \\
\hline
\end{tabular}

There is a statistically significant correlation between age of the age patient and the time taken for union.

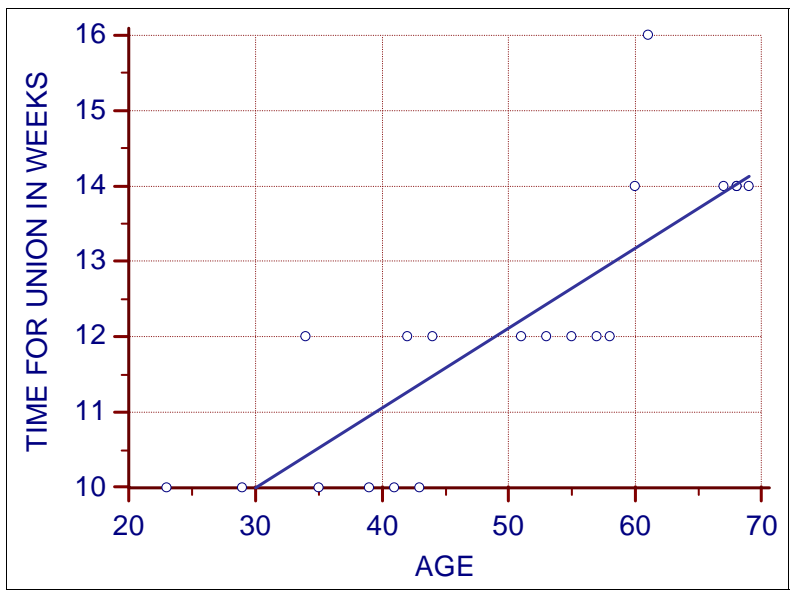

Scatter diagram

Correlation

\begin{tabular}{|c|c|}
\hline Variable Y & $\begin{array}{c}\text { Time_For_Union_In_Weeks } \\
\text { Time For Union In Weeks }\end{array}$ \\
\hline Variable X & Age \\
\hline
\end{tabular}

\begin{tabular}{|c|c|}
\hline Sample size & 20 \\
\hline Correlation coefficient $\mathrm{r}$ & 0.8290 \\
\hline Significance level & $\mathrm{P}<0.0001$ \\
\hline 95\% Confidence interval for $\mathrm{r}$ & 0.6105 to 0.9303 \\
\hline
\end{tabular}

\section{Regression}

\begin{tabular}{|c|c|}
\hline Dependent Y & $\begin{array}{c}\text { Time_For_Union_In_Weeks } \\
\text { Time For Union In Weeks }\end{array}$ \\
\hline Independent X & Age \\
\hline
\end{tabular}

There exists a positive regression between age and time for union 2. Age vs Aofas Score

\begin{tabular}{|c|c|c|c|c|c|c|}
\hline \multicolumn{7}{|c|}{ Aofas Score } \\
\hline & & & & & 95\% Confidenc & terval for Mean \\
\hline & $\mathbf{N}$ & Mean & Std. Deviation & Std. Error & Lower Bound & Upper Bound \\
\hline up to 40 years & 5 & 95.80 & 1.095 & .490 & 94.44 & 97.16 \\
\hline $41-60$ years & 10 & 93.40 & 1.647 & .521 & 92.22 & 94.58 \\
\hline 61 years $\&$ above & 5 & 87.80 & 4.604 & 2.059 & 82.08 & 93.52 \\
\hline Total & 20 & 92.60 & 3.885 & .869 & 90.78 & 94.42 \\
\hline
\end{tabular}




\begin{tabular}{|c|c|c|c|c|c|}
\hline \multicolumn{7}{|c|}{ Anova } \\
\hline \multicolumn{7}{|c|}{ Aofas Score } \\
\hline & Sum of Squares & Df & Mean Square & F & Sig. \\
\hline Between Groups & 172.800 & 2 & 86.400 & 12.884 & .000 \\
\hline Within Groups & 114.000 & 17 & 6.706 & & \\
\hline Total & 286.800 & 19 & & & \\
\hline
\end{tabular}

There is a statistically significant correlation between Age and the AOFAS score

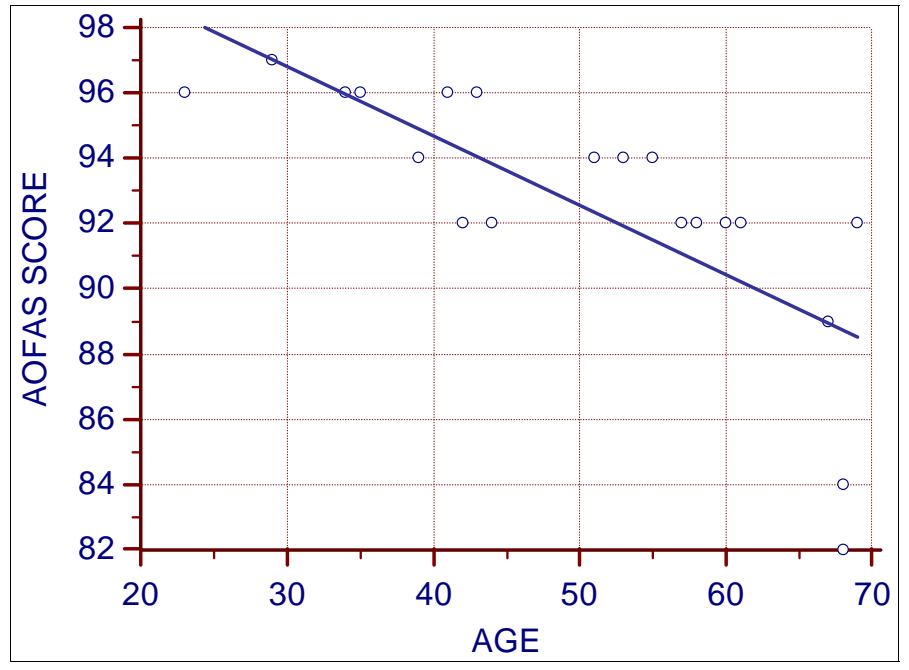

\section{Correlation}

\begin{tabular}{|c|c|}
\hline \multicolumn{1}{|c|}{ Variable $\mathrm{Y}$} & $\begin{array}{c}\text { Aofas_Score } \\
\text { Aofas Score }\end{array}$ \\
\hline Variable $\mathrm{X}$ & \multicolumn{2}{|c|}{ Age } \\
\hline \multicolumn{2}{|c|}{} \\
\hline Sample size & -0.7587 \\
\hline Correlation coefficient $\mathrm{r}$ & $\mathrm{P}=0.0001$ \\
\hline Significance level & -0.8993 to -0.4759 \\
\hline 95\% Confidence interval for $\mathrm{r}$ &
\end{tabular}

\section{Regression}

\begin{tabular}{|c|c|}
\hline Dependent Y & $\begin{array}{c}\text { Aofas_Score } \\
\text { Aofas Score }\end{array}$ \\
\hline Independent X & Age \\
\hline
\end{tabular}

\begin{tabular}{|c|c|}
\hline Sample size & 20 \\
\hline Coefficient of determination $\mathrm{R}^{2}$ & 0.5756 \\
\hline Residual standard deviation & 2.6005 \\
\hline
\end{tabular}

Scatter diagram indicates negative regression between age and AOFAS score. Greater the age lesser the score

\section{Weber type fracture vs aofas score}

\begin{tabular}{|c|c|c|c|c|c|c|}
\hline & \multicolumn{4}{|c|}{} & \multicolumn{2}{c|}{ 95\% Confidence Interval for Mean } \\
\hline & $\mathbf{N}$ & Mean & Std. Deviation & Std. Error & Lower Bound & Upper Bound \\
\hline 2 & 13 & 91.77 & 4.400 & 1.220 & 89.11 & 94.43 \\
\hline 3 & 7 & 94.14 & 2.193 & .829 & 92.11 & 96.17 \\
\hline Total & 20 & 92.60 & 3.885 & .869 & 90.78 & 94.42 \\
\hline
\end{tabular}

\begin{tabular}{|c|c|c|c|c|c|}
\hline \multicolumn{7}{|c|}{ Aofas Score } \\
\hline & Sum of Squares & Df & Mean Square & F & Sig. \\
\hline Between Groups & 25.635 & 1 & 25.635 & 1.767 & $\underline{.200}$ \\
\hline Within Groups & 261.165 & 18 & 14.509 & & \\
\hline Total & 286.800 & 19 & & & \\
\hline
\end{tabular}

There is no statistical significance between Weber type fracture and AOFAS score 


\section{Time for union vs aofas score Correlation}

\begin{tabular}{|c|c|}
\hline Variable Y & $\begin{array}{c}\text { Aofas_Score } \\
\text { Aofas Score }\end{array}$ \\
\hline Variable X & $\begin{array}{c}\text { Time_For_Union_In_Weeks } \\
\text { Time For Union In Weeks }\end{array}$ \\
\hline
\end{tabular}

\begin{tabular}{|c|c|}
\hline Sample size & 20 \\
\hline Correlation coefficient $\mathrm{r}$ & -0.6811 \\
\hline Significance level & $\mathrm{P}=0.0009$ \\
\hline 95\% Confidence interval for $\mathrm{r}$ & -0.8634 to -0.3415 \\
\hline
\end{tabular}

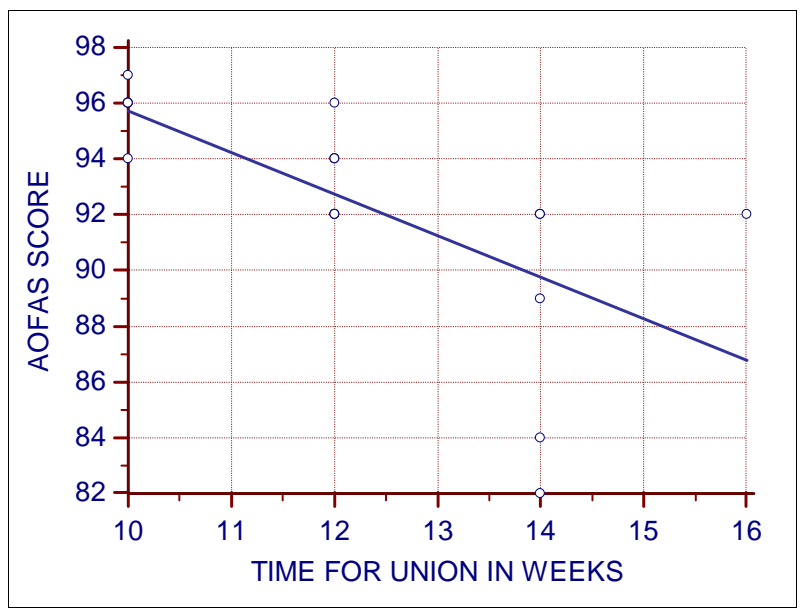

There is a statistically significant correlation between Time for union and AOFAS score. Earlier the union better the AOFAS scores.

\section{Discussion}

The important aspect of using a locking compression plate is the ability to use two different anchorage technologies by using a single implant. The LCP can be used either as a locked internal fixator or simply as a compression plate based on the patients requirement.

Conventionally bicortical fixation of the distal fibula has got three times the pull out strength when compared to unicortical purchase. Due to anatomical constraints the fixation of the distal periarticular region of the fibula should be restricted to unicortical screw application. When using conventional plating, such a unicortical fixation in the distal fragment will lead to increased rates of implant failure. When compared to the conventional plating techniques the use of LCP is independent of the bone mineral density status ${ }^{[5,6]}$.

Similar to external fixator, the LCP can function as a fixed angle construct. The fixed angle construct obviates the need of having compression effect between the plate and the bone. It also prevents toggling and screw back out happening due to micro motion, osteopenia induced by stress shielding effect. One of the major concern in using a LCP for distal fibula fracture is the hardware prominence on the lateral side and chance of wound gaping and infection. Decreased operative time, adequate soft tissue cover with proper skin closure, providing adequate antibiotic cover, limb elevation and antiedema measures post operatively has helped better in preventing wound related complications.

Studies have clearly shown that syndesmosis functions in a dynamic fashion during normal ankle motion. During motion fibula descends distally, laterally with a rotational component. This has led to the fixation of syndesmotic injuries which maintains the dynamic properties of the joint.
The ideal implant to be used for syndesmotic injuries should prevent late diastasis and help in early return to activity. The need for implant removal, chances of screw breakage and related complications can be avoided by using the suture button as the fixation device

With regards to the complication in our study, one case underwent similar fixation of the distal fibula and syndesmotic fixation. The patient was having uncontrolled diabetes mellitus and did not come for periodic follow up as advised. Patient developed superficial infection for which culture specific antibiotics were given, and infection controlled after 2 months. He had repetitive infection in surgical scar site followed by a formation of a sinus which was controlled by antibiotics alone. Implant exit was done finally. Patient did not have any functional limitations and was able to do his day to day activities without any hindrance. At the end of 6 months his AOFAS score was 82. This was the lowest score observed in our study.

The application of the suture button is an easy procedure without any technical difficulties and no additional special device is required except an introducer. The suture is unlikely to fatigue easily, hence implant removal is routinely not required. The patients can begin their rehabilitational activities at an earlier stage as the suture device exactly simulates the role carried out by the ligaments.

\section{Summary}

At the end of the study we had 20 cases in the follow up stage out of which 12 were male and 8 were females. The average age of the cases was 49.5 years ranging between 23-68 years. The mean of the time taken before surgery was 4.77 days (range 2-14 days).

The commonest fracture pattern was that of Weber type B with 13 cases with the remaining 7 cases being Weber type $C$ fractures.

The most common associated fracture was a medial malleolus fracture in 18 cases of various patterns, one case had an associated distal fibula fracture and on case had an isolated fibula fracture alone.

All the cases achieved radiological union and resumes their activities at an average of 12.1 weeks with a range between 10-16 weeks.

The average AOFAS score was found to be 92.6 with scores ranging from 82-97.

17 cases had excellent outcome and 3 cases had good outcome.

No routine removal was done for any of the cases, none of the cases had any intraoperative complications during the procedure.

One of the patient postoperatively developed a superficial skin infection due to poor hygiene which was controlled by good wound care and intravenous antibiotic cover. However the patient due to poor hygiene and uncontrolled diabetes mellitus repeatedly got superficial infection and finally implant removal was done for the patient after signs of radiological union was observed.

However that patient did not have any functional disability. He did not have any disabling pain and was able to do his day to day activities with mild discomfort. He was able to achieve an AOFAS score of 82.

No other major complications were observed itntraoperatively and post- operatively. No case was reported to have any activity restriction or a fair or poor outcome.

None of the cases were reported to have any neurovascular complications, non-union, malunion and implant failure. 


\section{Conclusion}

The fixation of distal fibula fractures with syndesmotic injury with anatomical Locking compression plate and syndesmotic suture button fixation is an effective method of fixation in view of

- Excellent fracture union

- Early rehabilitation

- Better fixation in comminuted and small distal fragment.

- Better fixation in osteoporotic bones

- Improved ankle stability

- Avoidance of syndesmotic screw related complications

- Lesser morbidity

- Fewer complications

\section{References}

1. Hopkinson WJ, St Pierre P, Ryan JB. syndesmotic sprains of the ankle. Journal of Foot and Ankle. 1990.

2. Rockwood and Green. Fractures in adults, 8th ed., 2015.

3. Ramsey PL, Hamilton. Changes in Tibiotalar Area of Contact Caused by Lateral Talar Shift, 56 ed.: TheJournal of Bone and Joint Surgery (American), 1976.

4. Phillips WA, Schwartz HS, Keller CS et al. A Prospective, Randomized Study of the Management of Severe Ankle Fractures. The Journal of Bone and Joint Surgery. 1985.

5. Zahn RK, Frey S, Jakubietz RG, Jakubietz MG, Doht S, Schneider $\mathrm{P}$ et al. A contoured locking plate for distal fibular fractures in osteoporotic bone: a biomechanical cadaver study. The Journal of Bone and Joint injury. 2012.

6. Kim T, Ayturk UM, Haskell A, Miclau T, Puttlitz CM. Fixation of osteoporotic distal fibula fractures: A biomechanical comparison of locking versus conventional plates. The Journal of Foot and Ankle surgery. 2007.

7. ZeYu Huang, Lei LiuEmail, ChongQi Tu, Hui Zhang, Yue Fang, TianFu Yang et al. Comparison of three plate system for lateral malleolar fixation. BMC Musculoskeletal Disorders, 2014.

8. Beris AE, Kabbani KT, Xenakis TA et al. Surgical treatment of malleolar fractures: A review of 144 patients. Journal of clinical orthopaedics. 1997.

9. De Souza LJ, Gustilo RB, Meyer TJ. Results of operative treatment of displaced external rotation-abduction fractures of the ankle. Journal of Bone and joint surgery. 1985.

10. Klitzman R, Zhao H, Zhang LQ, Strohmeyer G, Vora A. Suturebutton versus screw fixation of the syndesmosis: a biomechanical analysis. Journal of Foot and Ankle. 2010.

11. Thornes B, Shannon F, Guiney AM, Hession P, Masterson E. Suturebutton versus screw fixation of the syndesmosis: a biomechanical analysis. Clin Orthop Relat Res, 2005.

12. Coetzee JC, Ebeling P. Treatment of Syndesmosis Distruptions with Tight Rope Fixation. Clin Orthop Relat Res, 2008.

13. Richter M, Thermann H, Heufner T, Schmidt U, Goseling Krettek. Chopart joint fracture dislocation, initial open reduction gives better outcome than closed reduction. Journal of Foot and Ankle international. 2004.

14. Kelkian H, Kelkian S. Disorders of the ankle. : Saunders Company, 1985.

15. Heim U. Malleolar Fractures in adults, 1983.

16. Oglivie Harris DJ, Reed SC, Hedman TP. Disruption of the ankle syndesmosis - biomechanical study of the ligamentous restraints. Journal of Foot and Ankle surgery. 1994.

17. Ahl T, Dalen N, Lundberg A et al. Mobility of the ankle mortise. A roentgen stereophotogrammetric analysis. Acta Orthop Scand, 1987.

18. Henkemeyer U, Puschel R, Burri C. Experimentelle Untersuchungen zur Biomechanik der Syndesmose. Langenbecks Arch Chir Suppl Forum, 1975.

19. Lauge $\mathrm{N}$ et al. Fractures of the ankle, analytical history survey as the basis of experimental, roentenologic and clinical investigations. Arch Surgery, 1948.

20. Court-Brown CM, Caesar. Epdemiology of adult fractures a review, 2006.

21. Court-Brown CM, Wood AM, Aitken S. The Epidemiology of acute sports related fractures in adults, 2008.

22. Lin CF, Gross MT, Weinhold P. Ankle Syndesmosis Injuries: Anatomy, Biomechanism of Injury, and Clinical Guidelines for Diagnosis and Intervention. Journal of Orthopaedics and sports physiotheraphy, 2006.

23. Zalavras C, Thordarson D. Ankle syndesmotic injury. Journal of Am academy of orthopaedic surgery, 2007.

24. Najibi R, Banglemeier JM, Matta Tannest. Material properties of common suture materials in orthopaedic surgery. The IOWA orthopaedic Journal. 2010.

25. McKenna PB, O’Shea K, Burke T. Less is more: lag screw only fixation of lateral malleolar fractures. Int Orthop, 2007. 